\title{
Full-annual demography and seasonal cycles in a resident vertebrate
}

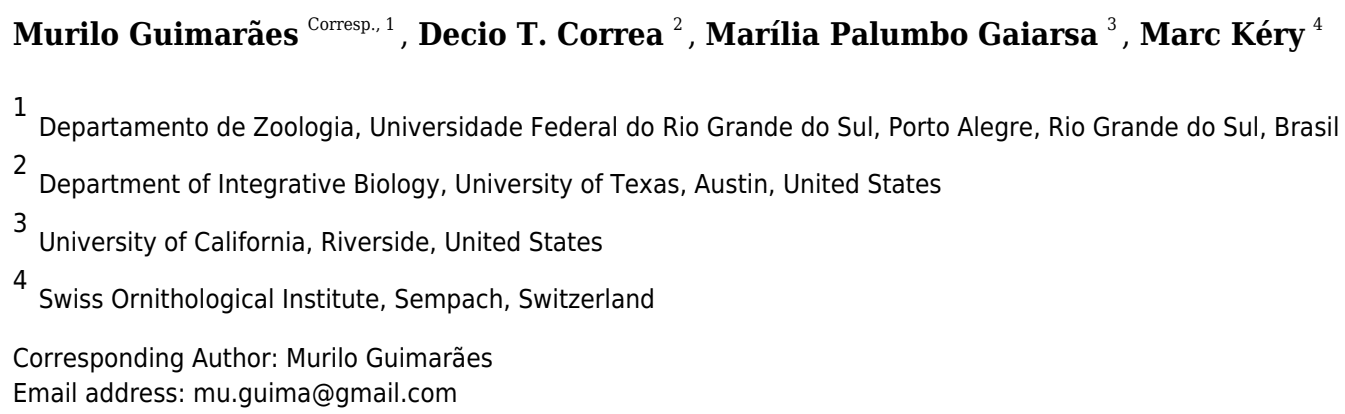

Wildlife demography is typically studied at a single point in time within a year when species, often during the reproductive season, are more active and therefore easier to find. However, this provides only a low-resolution glimpse into demographic temporal patterns over time and may hamper a more complete understanding of the population dynamics of a species over the full annual cycle. The full annual cycle is often influenced by environmental seasonality, which induces a cyclic behavior in many species. However, cycles have rarely been explicitly included in models for demographic parameters, and most information on full annual cycle demography is restricted to migratory species. Here we used a high-resolution capture-recapture study of a resident tropical lizard to assess the full intra-annual demography and within-year periodicity in survival, temporary emigration and recapture probabilities. We found important variation over the annual cycle and up to $92 \%$ of the total monthly variation explained by cycles. Fine-scale demographic studies and assessments on the importance of cycles within parameters may be powerful to achieve a better understanding of population persistence over time. 


\section{Full-annual demography and seasonal cycles in a resident vertebrate}

2 Murilo Guimarães ${ }^{1}$, Decio T. Correa ${ }^{2}$, Marília Palumbo Gaiarsa ${ }^{3}$, Marc Kéry ${ }^{4}$

$3{ }^{1}$ Departamento de Zoologia, Universidade Federal do Rio Grande do Sul, Porto Alegre-RS,

4 Brazil

$5 \quad{ }^{2}$ Department of Integrative Biology, University of Texas, Austin, United States

6 3University of California, Riverside, United States

$7 \quad{ }^{4}$ Swiss Ornithological Institute, Sempach, Switzerland

8

9 Corresponding author:

10 Murilo Guimarães ${ }^{1}$

11 Avenida Bento Gonçalves, 9500, Porto Alegre, RS, 91509-900, Brazil

12 Email address: mu.guima@gmail.com

13

14

15

16

17

18

19

20

21

22

23

24

Peer] reviewing PDF | (2019:09:41212:1:2:NEW 26 Dec 2019) 


\section{Abstract}

26 Wildife demography is typically studied at a single point in time within a year when species,

27 often during the reproductive season, are more active and therefore easier to find. However, this

28 provides only a low-resolution glimpse into demographic temporal patterns over time and may

29 hamper a more complete understanding of the population dynamics of a species over the full

30 annual cycle. The full annual cycle is often influenced by environmental seasonality, which

31 induces a cyclic behavior in many species. However, cycles have rarely been explicitly included

32 in models for demographic parameters, and most information on full annual cycle demography is

33 restricted to migratory species. Here we used a high-resolution capture-recapture study of a

34 resident tropical lizard to assess the full intra-annual demography and within-year periodicity in

35 survival, temporary emigration and recapture probabilities. We found important variation over

36 the annual cycle and up to $92 \%$ of the total monthly variation explained by cycles. Fine-scale

37 demographic studies and assessments on the importance of cycles within parameters may be

38 powerful to achieve a better understanding of population persistence over time. 
66

\section{Introduction}

Wildlife demography encompasses the study of four vital rates that underlie numerical change in populations: birth, death, immigration and emigration (Conroy and Carroll 2009).

Understanding spatial and temporal patterns in these rates is essential for both ecology and management of living species; yet, we often lack sufficient resolution in our observations for a complete description of the demography of a species. For instance, studies on animal population dynamics usually focus on specific periods of the annual cycle (Doherty and Grubb 2002; Singer et al. 1997), such as the breeding season, when a more sedentary lifestyle and increased activity increase the probability of detecting or catching individuals (Marra et al. 2015). This is the case for studies reporting individual variation in vital rates, such as survival probability (Grosbois et al. 2008), where individuals must be followed in the field over long periods (Lebreton et al. 1992). Although important, studies focusing on short periods typically can contribute less to our understanding of fundamental biological questions (Marra et al. 2015 and references therein). Studies focusing on short periods or yearly effects may be useful to track population demography and dynamics over years. However, such studies may mask within-year variations, reducing the number of statistical points to document temporal variability and preventing identification of the most critical periods of the year (Grosbois et al. 2008). Recently, Marra et al. (2015) have emphasized the importance of events beyond the breeding season and argued in favor of demographic research during the full annual cycle to fully understand the population dynamics of a species (Marra et al. 2015). outside of the breeding season (Hostetler et al. 2015), which for the vast majority of vertebrates extends for a period of one year, representing one time unit. Although more expensive and time 
consuming than assessments made only during a single period within a year, models describing events over the full annual cycle are useful both for theoretical and applied questions including carry-over effects (Harrison et al. 2011), and detection of population trends (reviewed in Hostetler et al. 2015; Marra et al. 2015). Most demographic models considering the full annual cycle have been applied to long-distance migratory species (Hostetler et al. 2015), especially birds (Culp et al. 2017; Rushing et al. 2017, but see Flockhart et al. 2015), although studies on resident species are also found for different taxa (Julliard et al. 1999; Martins et al. 2017;

Rodrigues et al. 2013). Resident species may offer better opportunities to study demography at a fine temporal scale, and may be subject to seasonal fluctuations due to less favorable periods for activity (Navas and Carvalho 2010), even in tropical areas (Dingle and Drake 2007).

Seasonal oscillations are expected for all living organisms (Panda et al. 2002) and are intrinsically connected to variability in temporal predictors, such as photoperiod (Bradshaw and Holzapfel 2007), moon phase (Hauenschild 1960), temperature (Brown et al. 2004) and rainfall (Chaplin 2001). Temporal predictors may be useful in revealing proximate or ultimate drivers of temporal variability, and are commonly employed to explain individual activity and population demography. However, temporal predictors are not always available or the relationship between such candidate predictors and temporal variability may not be clear (Crespin et al. 2002). Finally, temporal predictors may suffer from parameter estimability and are related to temporal variables, not to time itself (Fidino and Magle 2017).

Within-year periodicity may often be fairly predictable, and accounting for such cyclicity in demographic rates may be better achieved by explicitly including cycles in population dynamics parameters. However, population dynamics models do not make extensive use of explicit within-season cycles and therefore, little is known about the magnitude of potential 
92 cyclic variation in population dynamics (Webster et al. 2002; Wingfield 2008; Hostetler et al.

93 2015; Marra et al. 2015). Here we explore the full annual cycle and demonstrate periodicity may

94 be intrinsic in vital parameters. We investigate fine-scale, intra-annual demography using a

95 resident vertebrate, the neotropical whiptail lizard, Ameivula ocellifera, through an intensive

96 robust capture-recapture study (Pollock 1982; Kendall et al. 1997; Rankin et al. 2016). We first

97 describe the temporal variation throughout the annual cycle, and then, we evaluate the presence

98 and magnitude of cyclic effects in demographic parameters of this resident neotropical species.

\section{Methods}

\section{Study site and species}

We conducted the study in the Estação Ecológica de Jataí (21 $37^{\prime} 3$ ” S, $\left.47^{\circ} 45^{\prime} 55^{\prime \prime} \mathrm{W}\right)$, a transitional area between the Cerrado and the Atlantic Forest biomes in the state of São Paulo, SE Brazil. Mean temperatures vary between $11{ }^{\circ} \mathrm{C}$ and $30{ }^{\circ} \mathrm{C}$ in the coldest and hottest months, respectively. Annual rainfall is around $1500 \mathrm{~mm}$, mostly concentrated in the rainy season, from October to March (Cepagri 2011).

Snout-vent length), and heliophilous Teiidae lizard that occurs in most parts of tropical Brazil (Mesquita and Colli 2003). Individuals are active year-round, especially in the rainy season

110 (austral spring-summer) when breeding occurs. Newborns are found in the austral summer, from 111 January to March (Guimarães et al. 2017). More details about the species may be found in 112 Mesquita \& Colli (2003).

\section{Sampling design}


We sampled the population using a regular, square trapping grid consisting of 121 pitfall

115

116

117

118

119

120

121

122

123

124

125

126

127

128

129

130

131

132

133

134

135

136

traps 25 m apart, over 6.2 ha, from September 2010 to September 2011, capturing individuals for

seven consecutive days in each of 13 consecutive months. We used digital photography and

batch marking, by clipping the third joint of the second toe of the right hand (ICMBio Animal

Welfare Permit 10423-1) to recognize individuals. On each capture, we determined sex and assigned individuals to three sex/age classes: adult males (SVL $>40 \mathrm{~mm}$ ), adult females (SVL >

$51 \mathrm{~mm}$ ), and newborns (SVL $<37 \mathrm{~mm}$; non-reproductive individuals in their first year,

characterized by the presence of umbilical scar). After capturing and marking, we released

individuals near the same trap where they had been caught. We used the Interactive

Identification System software (Van Tienhoven et al. 2007) to identify individuals based on color and scale patterns. For more details, see Guimarães et al. (2017).

\section{Statistical Analysis}

We modeled our mark-recapture data with the full-capture hierarchical robust design

(RD) model (Rankin et al. 2016) and used a Bayesian mode of inference with MCMC

techniques, to assess the effects of temporal variation on demographic parameters. The RD

model distinguishes primary periods (here a 7-day period), between which a population is

assumed to be open, and nested secondary periods (here, daily capture occasions), during which

the population is assumed to be closed.

We distinguished three demographic groups in our analyses: adult males, adult females, newborns. We expected different demographic rates for them and therefore, in our models, we stratified all parameters by these groups. In our analysis, we focused on three main biological parameters in the models: apparent survival probability ( $\varphi$, hereafter 'survival'), which is the product of true survival and site fidelity, and thus, permanent emigration and death are not 
137 distinguished; temporary emigration probability, the probability of temporarily leaving the study

138 site given the individual was onsite ( $\gamma$ ”, hereafter 'emigration'), and detection probability ( $p$,

139 hereafter, 'recapture'), the probability of recapturing an individual given it is onsite. We also

140 estimated abundances for group and month using parameter-expanded data augmentation (PX-

141 DA, Royle and Dorazio 2012), which we do not focus on here but describe in the Online

142 Appendix 1. Our model also provides the probability of staying off-site $\left(\gamma^{\prime}\right)$, given an individual

143 was already off-site in the previous sampling occasion, and the probability of entering the study

144 site over time (pent). The parameter $\gamma^{\prime}$ is hard to estimate and pent is really more a nuisance

145 parameter than of real biological interest (Rankin et al. 2016). Therefore, we do not discuss them

146 in any detail.

We fit two variants of the RD model to our data that only differ in terms of the

specification of the time variation in the parameters. In model 1, time was included as a random

effect in the three parameters survival, emigration and recapture. That is, in this model we

allowed parameters to be different for each month and to vary around a constant value according

151

152

153

154

155

156

157

158

159 to a random effect. In model 2, we added cyclic effects of time on the same three parameters, survival, emigration, and recapture, using a periodic trigonometric function of month, and on top of that specified monthly residuals, also as random effect (see also Flury and Levri 1999; Crespin et al. 2002). We added two effects of month into the linear predictor of these three parameters, as follows: alpha $1 * \cos \left(2 * p i * \frac{m o n t h}{T}\right)+\operatorname{alpha} 2 * \sin \left(2 * p i * \frac{m o n t h}{T}\right)$ where $p i$ is the number $\mathrm{Pi}$, month corresponds to the month number between 1 (January) and 12 (December), $T$ represents the length of the periodic response (here $T=12$ ), and alphal and alpha2 are the two coefficients associated with the covariate 'month'. In this formulation, month/T tells us how far through the full annual cycle of $2 *$ pi each month is (see model code in the Online Appendix 2). In model 2, 
160 the proportional reduction in the among-month variation achieved by specification of the cyclic

161 patterns in these parameters enabled us to quantify the proportion of the among-month variation

162 that could be explained by the cycles (Kéry and Schaub 2012). Both models were built together,

163 in an a priori comparison.

164 We used vague priors and hyperpriors for all parameters, which we show in the Online

165 Appendix 2. We fit our models in the BUGS language (Lunn et al. 2000) using program JAGS

166 (Plummer 2003), run from R (R Core Team 2018) through the jagsUI interface (Kellner 2014).

167 We ran three chains with 400,000 iterations each, discarding 300,000 as burn-in and thinning at a

168 rate of 1 in 100 . We determined chain convergence by visual examination of trace plots and by

169 the Brooks-Gelman-Rubin statistic (Brooks and Gelman 1998), which was $<1.1$ for all

170 parameters. We present posterior means and 95\% credible intervals (CRI).

\section{Results} individuals. Fifty-one adult males, 29 adult females and 14 newborns were recaptured at least once. was higher for adult males (0.94, CRI 0.81-0.99) and adult females (0.90, CRI 0.72-0.99) than

179 for newborns $(0.64$, CRI 0.17-0.96). We observed considerable variability in survival during the course of a year, where adults of both sexes presented similar patterns through the year, and newborns showed a sharp decrease after hatchling, in the month of March (Fig. 1). Under model 
1821 , mean annual survival during our study was $0.17(0.01-0.39)$ for males, $0.18(0.01-0.60)$ for

183 females and $0.002(5.62 \mathrm{e}-12-0.02)$ for newborns.

184 The newborns showed the highest probability of emigration (0.32, CRI 0.01-0.85),

185 followed by adult females (0.16, CRI 0.03-0.63) and males (0.15, CRI 0.042-0.66, Fig. 1). Daily

186 mean recapture probabilities were similar in all three groups with small variations during the

187 year, where males and newborns presented the highest rates during the breeding season, at the

188 beginning and in the end, respectively (Fig. 1).

Model 2 (with cycles added) revealed a strong periodicity in all three parameters that we modeled with a cosine periodic function of the month (survival, emigration and recapture; Fig.

1). Comparisons of the magnitude of the (residual) among-month variance between models 2 and 1 showed that annual cycles explained $92.5 \%$ of the monthly variation in apparent survival, $86.8 \%$ in emigration probability, and $84.6 \%$ in recapture probability.

Discussion

Many population dynamics studies are based on the observation of a population just once a year, often during the breeding season. Recently, it has been pointed out that studies with high temporal resolution are required to fully understand population dynamics, so are models covering the full annual cycle of a species, i.e., with multiple samplings a year (Hostetler et al. 2015; Marra et al. 2015). Here, we modeled fine-scale temporal variability in the vital rates of a resident species and assessed the population throughout the year, including low-activity periods. We showed that demographic parameters varied along the full annual cycle in a cyclic fashion, suggesting that the strong periodic signal found in those vital parameters could be associated to 
204 long-term demography. Our findings provide detailed information on the population biology of a 205 species and were only possible due to the high-temporal resolution of demographic information 206 for an entire annual cycle.

\section{The full annual cycle reveals detailed information on species biology}

Survival estimates for the vast majority of the $\sim 6,500$ species of lizards worldwide are

209

210

211

212

214

215

216

217

218

219

220

221

222

223

224

225

226 lacking, but general patterns have emerged based on life history traits, including foraging mode and mating system. Our results contribute to the relationship between clutch size and growth rate - the classical slow-fast continuum -, which finds support in lizard natural history where early investments in rapid growth may decrease late survival (Clobert et al. 1998; Olsson and Shine 2002). Survival in slow-growing, territorial lizards from the Iguania clade are said to be higher (Ujvari et al. 2015; Iverson et al. 2016; Keehn et al. 2019), than in the non-territorial Scleroglossa clade, to which the Teiidae family belongs (Pianka and Vitt 2003). Males from Teiidae species can present female accompaniment (Pianka and Vitt 2003) and fight conspecific males to guard females, which may impair survival (Ancona et al. 2010). Females in turn, may also pay a high survival cost in the breeding season due to basking activity and low mobility (Shine 1980). After the breeding season, we found that survival dropped $30 \%$ for adult males and $35 \%$ for adult females. Thus, carry over effects due to the costs of reproduction may affect future short-term and long-term survival. Although the duration of our study prevents us from linking the observed increased mortality to costs of reproduction, the full annual cycle research may be promising to uncover sources of mortality in species.

Temporary emigration for adults was the highest after the mating and hatchling periods, coinciding with the beginning of the dry and cold season. Energetic reserves may be depleted after the mating season (Shine 1980) and we found several individuals buried 10-20 cm below 
227 ground in our study site during this period of the annual cycle. Additionally, most individuals

228 recaptured in our study were found up to $50 \mathrm{~m}$ from the trap they were first caught and similar

229 home ranges were already reported for other Teiidae lizards (Hernández-Gallegos et al. 2018;

230 Winck et al. 2011). Considering that site fidelity may be high in the studied species, vertical

231 migration could explain temporary emigration. Temporary emigration probability of newborns

232 was up to four times higher than that of adults, explaining, at least in part, the scarcity of juvenile

233 demographic information that is common across taxonomic groups, because most juvenile

234 individuals are just unavailable for capture. This pattern is usually attributed to a variety of

235 aspects, including smaller body sizes, secretive and inconspicuous habits, and high mortality

236 rates (Rivas et al. 2016; Bailey et al. 2017; Wilson et al. 2018).

237 Adult males presented the highest recapture rates at the onset of the breeding season,

238 coinciding with high mating activity rates during this period. Since our trap system was

239 stationary, we expect capture rates to increase with activity, and in this case, detection

240 probability parameter of a capture-recapture model is not merely a nuisance parameter. More

241 than that, detection probability is a parameter with a biological meaning, related to physical

242 activity, which produces a strong signal in the detection probability of species (Strebel et al.

243 2014; Sutherland et al. 2016). However, detection probability may be also related to other

244 characteristics, such as capture effort and trapping methods. In territorial species, males may

245 present higher recapture rates than females due to greater site fidelity. Overall, our mean

246 recapture estimates were similar across groups. Given that this species feeds primarily on

247 termites, where all individuals actively forage in open areas (Mesquita and Colli 2003), our

248 results may be related to their feeding behavior and the absence of territoriality (Pianka and Vitt 249 2003). 


\section{Periodicity can be strong in demographic rates}

251 Cyclicity is found in endogenous rhythms of every life form, from cells to individuals,

252 and the biological clock is influenced by exogenous rhythms, such as Earth's rotation and

253 climate, to maximize fitness (Panda et al. 2002; Wingfield 2008). This explains, at least in part,

254 why activity in many organisms is concentrated in short time frames, such as breeding events

255 (Bradshaw and Holzapfel 2007; Harrison et al. 2011; Marra et al. 2015). Although the full annual

256 cycle is mostly described for long-distance migratory species, where individuals are

257 unobservable for some time, tropical species may also be subject to periodicity due to temporary

258 absences, involving reduced activity and unavailability.

259 Surprisingly, few studies exploring the life cycle of a species have actually fitted cyclic

260 patterns in demographic rates. If we assume that the beginning of a temporal pattern in a

261 parameter to "meet" with the end of it over the course of a year, such cycles are almost to be

262 expected. Periodicity may occur at different time scales, such as observed in the daily activity of

263 the New Zeland mudsnails (Flury and Levri 1999), or in the yearly activity of American

264 mesocarnivore mammals, with up to $75 \%$ of temporal variability in colonization rates explained

265 by cyclicity (Fidino and Magle 2017). We fitted cycles in three demographic parameters

266 (apparent survival, emigration probability and recapture rate) and found strong evidence of

267 annual periodicity, with cycles explaining on average a remarkable $88 \%$ of the total variation

268 among months. We are aware that the observed variability in the demographic parameters was

269 based on only one full cycle, preventing us from claiming that the patterns found here represents

270 long-term variability. However, the monthly variation we found supports the cyclicity of life

271 forms suggesting that the within-year pattern observed may be seen among years as well.

272 Detailed, multi-year information on population demography may support our findings on the 
273 magnitude of specie's annual cycles, which could be of great use to wildlife management and

274 conservation.

275

276

277

278

279

280

281

282

283

284

285

286

287

288

289

290

291

292

293

In the face of rapid biodiversity declines, information on individuals and populations are essential for conservation purposes. Between-year and within-year population assessments may uncover different aspects of population demography and dynamics. For example, bank vole populations were manly driven by the acorn mast crop production from year to year, whereas within-year variation was mainly attributed to emigration, a population intrinsic factor (Crespin et al. 2002). Between-year estimates may be useful to assess population growth over years while within-year population assessments may reveal the most sensitive periods of the full annual cycle. In this way, full annual cyclic modeling, the combination of full annual cycle research with cyclic parameter estimation, can be powerful to uncover critical points in the trajectory of populations, supporting decision-making actions.

\section{Conclusions}

We endorse the use of full annual cycle studies of species, and suggest that investigations on resident species may provide cheaper fine-scale information than long-distant migratory species. With our results, we raise the possibility that intra-annual temporal variability in demographic rates may be highly cyclic. Periodicity should be more explored in vital rate assessments, and here we claim for its inclusion in population demography as a venue for predictive studies. Fluctuations may be triggered by many different sources, and understanding the mechanisms that regulate populations over time is of fundamental importance to ensure the 
294 persistence of species. Full annual cyclic modeling may be important to predict future population

295 oscillations and raise important insights, even when they explain little variability.

296

\section{Acknowledgements}

298

299

300

301

302

303

304

305

306

307

308

309

310

311

312

313

314

315

316

We thank Robert Rankin and Brett McClintock for advice on statistical analysis. Ricardo

Sawaya, Hamanda B. Cavalheri, Sérgio Serrano, Thiago Oliveira, Roberto Munguia Steyer, Glauco Machado and our field crew were especially kind and helpful during data collection. We also thank Jeffrey Hostetler, Nigel Yoccoz and an anonymous reviewer for valuable suggestions that improved our paper. The ICMBio provided the permission for data collection.

\section{References}

Ancona, S., Drummond, H., \& Zaldívar-Rae, J. (2010). Male whiptail lizards adjust energetically costly mate guarding to male-male competition and female reproductive value. Animal Behaviour, 79(1), 75-82. https://doi.org/10.1016/j.anbehav.2009.10.005

Bailey, A. M., McCleery, R. A., Ober, H. K., \& Pine, W. E. (2017). First demographic estimates for endangered Florida bonneted bats suggest year-round recruitment and low apparent survival. Journal of Mammalogy, 98(2), 551-559. https://doi.org/10.1093/jmammal/gyw198

Bradshaw, W. E., \& Holzapfel, C. M. (2007). Evolution of animal photoperiodism. Annual Review of Ecology, Evolution, and Systematics, 38(1), 1-25. https://doi.org/10.1146/annurev.ecolsys.37.091305.110115

Brooks, S. P., \& Gelman, A. (1998). General methods for monitoring convergence of iterative simulations. Journal of Computation and Graphical Statistics, 7(4), 434-455. https://doi.org/10.1080/10618600.1998.10474787 
317 Brown, J. H., Gillooly, J. F., Allen, A. P., Savage, V. M., \& West, G. B. (2004). Toward a

318 metabolic theory of ecology. Ecology, 85(7), 1771-1789.

319

320

321

322

323

324

325

326

327

328

329

330

331

332

333

334

335

336

337

338

339

340

341

342

343

Chaplin, M. F. (2001). Water: Its importance to life. Biochemistry and Molecular Biology Education, 29(2), 54-59. https://doi.org/10.1016/S1470-8175(01)00017-0

Clobert, J., Garland, Jr., T., \& Barbault, R. (1998). The evolution of demographic tactics in lizards: a test of some hypotheses concerning life history evolution. Journal of Evolutionary Biology, 11, 329-364.

Conroy, M. J., \& Carroll, J. P. (2009). Quantitative Conservation of Vertebrates. (M. J. Conroy \& J. P. Carroll, Eds.) (First). Oxford: Wiley-Blackwell.

Crespin, L., Verhagen, R., Stenseth, N. C., Yoccoz, N. G., Prévot-Julliard, A. C., \& Lebreton, J. D. (2002). Survival in fluctuating bank vole populations: Seasonal and yearly variations. Oikos, 98(3), 467-479. https://doi.org/10.1034/j.1600-0706.2002.980311.x

Culp, L. A., Cohen, E. B., Scarpignato, A. L., Thogmartin, W. E., \& Marra, P. P. (2017). Full annual cycle climate change vulnerability assessment for migratory birds. Ecosphere, 8(3), 1-22. https://doi.org/10.1002/ecs2.1565

Dingle, H., \& Drake, V. A. (2007). What is Migration? Canadian Studies in Population, 57(2), 113-121. https://doi.org/10.25336/p65s40

Doherty, P. F., \& Grubb, T. C. (2002). Survivorship of permanent-resident birds in a fragmented forested landscape. Ecology, 83(3), 844-857. https://doi.org/10.1890/00129658(2002)083[0844:SOPRBI]2.0.CO;2

Fidino, M., \& Magle, S. B. (2017). Using Fourier series to estimate periodic patterns in dynamic occupancy models. Ecosphere, 8(9). https://doi.org/10.1002/ecs2.1944

Flockhart, D. T. T., Pichancourt, J. B., Norris, D. R., \& Martin, T. G. (2015). Unravelling the annual cycle in a migratory animal: breeding-season habitat loss drives population declines of monarch butterflies. Journal of Animal Ecology, 84(1), 155-165. https://doi.org/10.1111/1365-2656.12253

Flury, B. D., \& Levri, E. P. (1999). Periodic logistic regression. Ecology, 80(7), 2254-2260. 
344 Grosbois, V., Gimenez, O., Gaillard, J. M., Pradel, R., Barbraud, C., Clobert, J., ...

345 Weimerskirch, H. (2008). Assessing the impact of climate variation on survival in vertebrate populations. Biological Reviews, 83(3), 357-399. https://doi.org/10.1111/j.1469-

348

349

350

351

352

353

354

355

356

357

358

359

360

361

362

363

364

365

366

367

368

369

370

371 185X.2008.00047.x

Guimarães, M., Munguía-Steyer, R., Doherty, P. F., \& Sawaya, R. J. (2017). No survival costs for sexually selected traits in a polygynous non-territorial lizard. Biological Journal of the Linnean Society, 122(3), 614-626. https://doi.org/10.1093/biolinnean/blx097

Harrison, X. A., Blount, J. D., Inger, R., Norris, D. R., \& Bearhop, S. (2011). Carry-over effects as drivers of fitness differences in animals. Journal of Animal Ecology, 80(1), 4-18. https://doi.org/10.1111/j.1365-2656.2010.01740.x

Hernández-Gallegos, O., López Moreno, A., Méndez de La Cruz, F., \& Walker, J. (2018). Home range of the parthenogenetic lizard Aspidoscelis maslini (FRiTTS, 1969), on a beach strand, 31(August), 83-86.

Hostetler, J. A., Sillett, T. S., \& Marra, P. P. (2015). Full-annual-cycle population models for migratory birds. The Auk, 132(2), 433-449. https://doi.org/10.1642/auk-14-211.1

Iverson, J. B., Smith, G. R., Pasachnik, S. A., Hines, K. N., \& Piepper, L. (2016). Growth, coloration, and demography of an introduced population of the Acklinns Rock Iguana (Cyclura rileyi nuchalis) in the Exuma Islands, The Bahamas. Herpetological Conservation and Biology, 11(November 2015), 139-153.

Julliard, R., Leirs, H., Stenseth, N. C., Yoccoz, N. G., Prévot-Julliard, A. C., Verhagen, R., \& Verheyen, W. (1999). Survival-variation within and between functional categories of the African multimammate rat. Journal of Animal Ecology, 68(3), 550-561. https://doi.org/10.1046/j.1365-2656.1999.00304.x

Keehn, J. E., Shoemaker, K. T., \& Feldman, C. R. (2019). Population-level effects of wind farms on a desert lizard. Journal of Wildlife Management, 83(1), 145-157. https://doi.org/10.1002/jwmg.21565

Kendall, W. L., Nichols, J. D., Hines, J. E., \& Mar, N. (1997). Estimating temporary emigration using capture-recapture data with Pollock's Robust Design. Ecology, 78(2), 563-578. 
372 Kéry, M., \& Schaub, M. (2012). Bayesian population analysis using WinBUGS. (M. Kéry \& M.

373 Schaub, Eds.) (First). Amsterdam: Elsevier. https://doi.org/10.1016/B978-0-12-387020-

374 9.00024-9

375

376

377

378

379

380

381

382

383

384

385

386

387

388

389

390

391

392

393

394

395

396

397

398

Lebreton, J.-D., Burnham, K. P., Clobert, J., \& Anderson, D. R. (1992). Modeling survival and testing biological hypotheses using marked animals: a unified approach with case studies. Ecological Monographs, 62(1), 67-118.

Lunn, D. J., Thomas, A., Best, N., \& Spiegelhalter, D. (2000). WinBUGS - a bayesian modelling framework: concepts, structure, and extensibility. Statistics and Computing, 10(4), 325337. https://doi.org/10.1023/A:1008929526011

Marra, P. P., Cohen, E. B., Loss, S. R., Rutter, J. E., \& Tonra, C. M. (2015). A call for full annual cycle research in animal ecology. Biology Letters, 11(8), 20150552. https://doi.org/10.1098/rsbl.2015.0552

Martins, L. F., Guimarães, M., \& Verrastro, L. (2017). Population estimates for the sand lizard, Liolaemus arambarensis: contributions to the conservation of an endemic species of Southern Brazil. Herpetologica, 73(1), 55-62. https://doi.org/10.1655/herpetologica-d-1600046.1

Mesquita, D. O., \& Colli, G. R. (2003). The Ecology of Cnemidophorus ocellifer (Squamata, Teiidae) in a Neotropical Savanna. Journal of Herpetology, 37(3), 498-509.

Navas, C. A., \& Carvalho, J. E. (2010). Aestivation: molecular and physiological aspects. (Carlos Arturo Navas \& J. E. Carvalho, Eds.) (First). Heildelberg: Springer. Retrieved from https://link-springer-com.kuleuven.ezproxy.kuleuven.be/content/pdf/10.1007\%2F978-3642-02421-4.pdf

Olsson, M., \& Shine, R. (2002). Growth to death in lizards. Evolution, 56(9), 1867-1870.

Panda, S., Hogenesch, J. B., \& Kay, S. A. (2002). Circadian rhythms from flies to human. Nature, 417(6886), 329-335. https://doi.org/10.1038/417329a

Pianka, E., \& Vitt, L. (2003). Lizards: windows to the evolution of diversity. (E. Pianka \& L. J. Vitt, Eds.). Berkeley: University California Press. 
399

400

401

402

403

404

405

406

407

408

409

410

411

412

413

414

415

416

417

418

419

420

421

422

423

424

425

426

Plummer, M. (2003). JAGS: a program for analysis of Bayesian graphical models using Gibbs sampling. In K. Hornik, F. Leisch, \& A. Zeileis (Eds.), 3rd International Workshop on Distributed Statistical Computing (Vol. 3, pp. 1-10). https://www.rproject.org/conferences/DSC-2003/. https://doi.org/ISSN 1609-395X

Pollock, K. H. (1982). A capture-recapture sampling design robust to unequeal catchability. Journal of Wildlife Management, 46, 752-757.

Rankin, R. W., Nicholson, K. E., Allen, S. J., Krützen, M., Bejder, L., \& Pollock, K. H. (2016). A Full-Capture Hierarchical Bayesian Model of Pollock's Closed Robust Design and Application to Dolphins. Frontiers in Marine Science, 3(March), 1-18. https://doi.org/10.3389/fmars.2016.00025

Rivas, J. A., Molina, C. R., Corey, S. J., \& Burghardt, G. M. (2016). Natural history of neonatal green anacondas ( Eunectes murinus ): a chip off the old block. Copeia, 104(2), 402-410. https://doi.org/10.1643/ce-15-238

Rodrigues, L. da C., Martins, F. I., \& Rodrigues, M. (2013). Survival of a mountaintop hummingbird, the hyacinth visorbearer Augastes scutatus, in southeastern Brazil. Acta Ornithologica, 48(2), 211-219. https://doi.org/10.3161/000164513x678801

Royle, J. A., \& Dorazio, R. M. (2012). Parameter-expanded data augmentation for Bayesian analysis of capture-recapture models. Journal of Ornithology, 152(SUPPL. 2), 521-537. https://doi.org/10.1007/s10336-010-0619-4

Rushing, C. S., Hostetler, J. A., Sillett, T. S., Marra, P. P., Rotenberg, J. A., \& Ryder, T. B. (2017). Spatial and temporal drivers of avian population dynamics across the annual cycle. Ecology, 98(11), 2837-2850. https://doi.org/10.1002/ecy.1967

Shine, R. (1980). "Costs" of reproduction in reptiles. Oecologia, 46, 92-100.

Singer, F. J., Harting, A., Symonds, K. K., \& Coughenour, M. B. (1997). Density dependence, compensation, and environmental effects on elk calf mortality in Yellowstone National Park. The Journal of Wildlife Management, 61(1), 12. https://doi.org/10.2307/3802410

Strebel, N., Kéry, M., Schaub, M., \& Schmid, H. (2014). Studying phenology by flexible modelling of seasonal detectability peaks. Methods in Ecology and Evolution, 5(5), 483- 
427

428

429

430

431

432

433

434

435

436

437

438

439

440

441

442

443

444

445

446

447

448

449

450

451

452

453

490. https://doi.org/10.1111/2041-210X.12175

Sutherland, C., Muñoz, D. J., Miller, D. A. W., \& Grant, E. H. C. (2016). Spatial CaptureRecapture: a promising method for analyzing data collected using artificial cover objects. Herpetologica, 72(1), 6. https://doi.org/10.1655/herpetologica-d-15-00027

Ujvari, B., Fisher, P., Rydell, J., Wahlgren, R., Wright, B., \& Madsen, T. (2015). Population demography of frillneck lizards (Chlamydosaurus kingii, Gray 1825) in the wet-dry tropics of Australia. Austral Ecology, 40(1), 60-66. https://doi.org/10.1111/aec.12168

Van Tienhoven, A. M., Den Hartog, J. E., Reijns, R. A., \& Peddemors, V. M. (2007). A computer-aided program for pattern-matching of natural marks on the spotted raggedtooth shark Carcharias taurus. Journal of Applied Ecology, 44(2), 273-280. https://doi.org/10.1111/j.1365-2664.2006.01273.x

Webster, M. S., Marra, P. P., Haig, S. M., Bensch, S., \& Holmes, R. T. (2002). Links between worlds: unraveling migratory connectivity. Trends in Ecology \& Evolution, 17(2), 1-8. Retrieved from http://ree.trends.com0169-5347/02/\$seefrontmatter\%0Apapers2://publication/uuid/46B94E68-8236-46CB-A8D1CFBB48B0168F

Wilson, S., Saracco, J. F., Krikun, R., Flockhart, D. T. T., Godwin, C. M., \& Foster, K. R. (2018). Drivers of demographic decline across the annual cycle of a threatened migratory bird. Scientific Reports, 8(1), 1-11. https://doi.org/10.1038/s41598-018-25633-z

Winck, G. R., Blanco, C. C., \& Cechin, S. Z. (2011). Population ecology of Tupinambis merianae (Squamata, Teiidae): Home-range, activity and space use. Animal Biology, 61(4), 493-510. https://doi.org/10.1163/157075511X597647

Wingfield, J. C. (2008). Organization of vertebrate annual cycles: implications for control mechanisms. Philosophical Transactions of the Royal Society B: Biological Sciences, 363(1490), 425-441. https://doi.org/10.1098/rstb.2007.2149

Peer) reviewing PDF | (2019:09:41212:1:2:NEW 26 Dec 2019) 
455

456

457

458

Figure Legend

459 Fig.1 Monthly probabilities of survival, emigration and recapture for adult males, adult females 460 and newborns Ameivula ocellifera, between September 2010 and September 2011. Panels A, B, 461 C: model based on random month effects only (model 1). Panels D, E, F: model based on cycles 462 plus random monthly deviations from these cycles (model 2). Vertical gray lines (A, B, C) and 463 shaded areas (D, E, F) represent 95\% credible intervals. 
Figure 1

Monthly probabilities of survival, emigration and recapture for adult males, adult females and newborns Ameivula ocellifera, between September 2010 and September 2011.

Panels A, B, C: model based on random month effects only (model 1). Panels D, E, F: model based on cycles plus random monthly deviations from these cycles (model 2). Vertical gray lines $(A, B, C)$ and shaded areas $(D, E, F)$ represent $95 \%$ credible intervals.

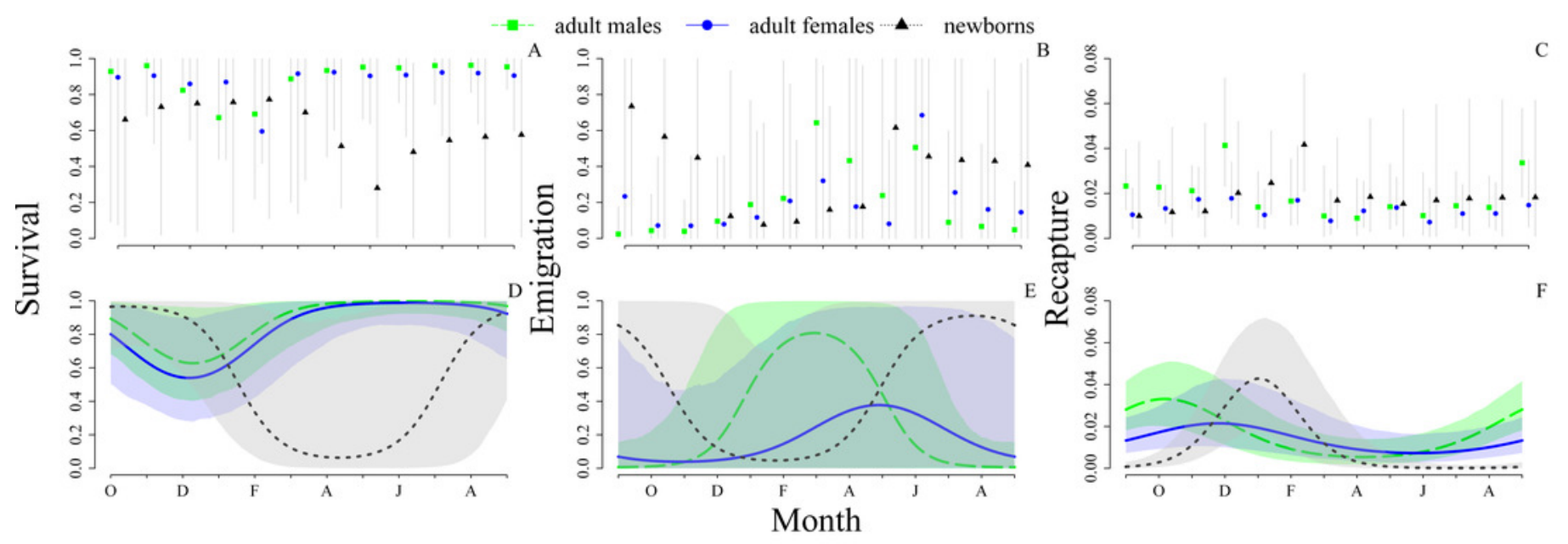

